\title{
Study on Water Landscape Sculpture in City Square
}

\author{
Lili Zhang \\ School of Art and Design \\ Lanzhou Jiaotong University \\ Lanzhou, China 730070
}

\begin{abstract}
Nowadays, urban construction develops increasingly. The city square has become an important place for people to entertain, so the landscape design of city square is very important, especially related design of water landscape sculpture. The water sculpture design is more important. The water landscape sculpture of city square is one of the important types of water landscapes in urban public space. Just as other water landscapes, its design needs to combine with basic elements of the city, fully considers surrounding landscape of city square and then ensures the water landscape sculpture design is more reasonable and better combines with the city and provides beautiful treat for urban residents. This article analyzes water landscape sculpture of city square, defines influencing factors and constituent elements of water landscape design of city square and comprehensively considers the influencing factors of water landscape sculpture design of city square, to ensure the water landscape sculpture of city square better meets the requirements of modern city people for beauty.
\end{abstract}

Keywords-city square; constituent elements; water landscape sculpture

\section{INTRODUCTION}

Water landscape of city square is one of the important types of water landscapes of city public space. The water landscape sculpture design of city square mainly uses water as the basic constituent element. Combining with other elements, it forms the overall water landscape of the city. It not only beautifies the city but also inherits the water landscape sculpture culture of our country, letting more people enjoy the beautiful scenery as well as understand the culture of our country. It is well-known that city gathers human culture. It belongs to a complicated organization and serves as social and ecological representative. So each constituent element inside the city is extremely important. If each element can meet the requirements of city beautification and culture, it can ensure the city becomes more reasonable and better meets the requirements of people for the beauty of cities.

\section{ANALYSIS ON THE RELATIONSHIP BETWEEN WATER LANDSCAPE OF CITY SQUARE AND CITY SQUARE}

From the perspective of urban space, city square is the representative of urban space with the most public character and artistic charm. It serves as a foil to fully embody city civilization and corresponding atmosphere. When designing water landscape of city square, it is necessary to ensure the form of water landscape can conform to formal beauty of the city and has harmonious relationship with the square, pay high attention to the rhyme and rhythm, the principle and the subordinate as well as the emphasis. Both the form of water landscape sculpture and the integrity of design need to start from the relationship between city square and the small sculpture of water landscape of city square. In this way, it can ensure the perfection of design. [1] It is well-known that the form of water body in the square depends on the enclosure of boundary, which can use hard material as well as natural elements. People show them to people through the square to realize beautiful design of water landscape sculpture.

According to the research, there are many definitions and classifications on the square. But on the basis of conditions expressed by it, the square includes buildings, road or some green belts. It mainly takes hard materials as the main paving materials. Vehicles shall not enter in the square. The square is mainly used by people to stroll, sit at leisure and have dinner. It is an important landscape of the city.

\section{ANALYSIS ON THE CHARACTERISTICS OF WATER LANDSCAPE SCULPTURE OF CITY SQUARE}

The water landscape sculpture of city square can carry out the activation of the space. It is public artwork with public participation.

The activation of the space mainly shows that in the environment of the square, people pay attention to the visual impact brought by the horizontal visual space environment and the degree of getting close to nature. In the square with limited space, we cannot embody natural landscape in it, so the water landscape sculpture design of the square cannot pursue the magnificent nature. The water landscape sculpture design in square space needs to expand and guide space and continuously enrich the contents of square landscape through diversified landscape area to activate the space. It is important content in water landscape sculpture design in the square as well as the embodiment of the most important characteristics.

The public artwork mainly shows that in water landscape sculpture design of city square, it has open space in the city. It is public-oriented and belongs to public artwork of the city. Public art mainly refers to artistic planning and design on the environment in urban construction. Urban open space belongs to important landscape of public place. Water landscape sculpture has certain artistic and aesthetic elements and belongs to important artwork on city square. It is the structure full of aesthetic feeling in city square. The static manifestation of water landscape sculpture of city square expresses cultural connotation of things through media; its dynamic 
manifestation is mainly embodied through social public cultural activities. Water landscape sculpture is one of the important works among public artistic works in the city. Its pattern of manifestation and using function can incisively and vividly express the rules and characteristics of public art.

Moreover, the water landscape in the square also has publicity. Its contents and forms serve the masses and have inseparable relationship with the life of city people. Therefore, related departments in the city should strengthen the management of city environment and ensure to provide people with graceful and closer environment and eliminate negative impacts on people so that people will be more satisfied about the environment of city square. [2] Actually, the nature of public art is to be close to civilian. It determines the city square should serve the public and seek benefits for the masses. From the material and spiritual perspectives, it is mainly people oriented.

The public participation mainly shows the users of the environment and urban residents participate in the whole process of city construction including the planning and investigation and conception of city square. The main purpose of "public participation" is to let ordinary people control the landscape of city square to some extent again. Designers are not the main body to determine the living environment of city people any more. In this way, it can arouse the creativity of people participating in the design of city square and create good conditions for the harmony and unity of city environment and buildings and finally design more stable and satisfied community environment.

The practice shows that public participation plays certain role in city design and planning. In city design, the design of some squares also has brought certain benefits. The square can truly reflect the degree of satisfaction of citizens. It is the most direct and feasible way. [3] Designers must care for people and solve problems raised by people in the design of city square and help them to understand problems. In this way, it can meet the design requirements of water landscape sculpture of city square and let the design and urban structure become more harmonious and conform to the demands of urban residents for city beauty.

\section{CURRENT Situation OF THE DESIGN OF WATER LANDSCAPE SCULPTURE OF CITY SQUARE}

At the present stage, the design of water landscape sculpture of city square has some problems, including:

\section{A. The Design Plans Have Similarities}

From the perspective of the water landscape sculpture design of city square, the design plans have many similarities. Many water landscape sculpture designs of city square imitate each other. So the design plans of water landscape sculpture design of city square of many cities cannot conform to the requirements of their own and local characteristic culture. They refer to the design plans of each other blindly. Finally, the water landscape designs of city square are the same. [4]

\section{B. The Operation of Water Landscape Structure Is not Appropriate on Dealing with Anti-seepage Problems}

In water landscape design of city square, the key point and difficult point is the anti-seepage treatment of water body. At present, the water landscape design of city square mainly uses rigid reinforced concrete to finish the anti-seepage operation. But in reality, the anti-seepage operation has problems. For example, the bottom structure is easy to leak or crack. At the meantime, it is difficult to find out these problems, which will cause very serious consequences. [5]

\section{The Water Landscape cannot Be Used Effectively for a Long Time}

The water landscape design of city square often focuses on landscape effects or the culture and takes the problems of water source and water quality into little consideration. The water does not have self cleaning capacity and will become black or muddy under the influence of unreasonable design and improper management. It has great negative impacts on the degree of city beauty. [6] It is similar to the opinions of Yin Xigang in Ecological Design of Water Landscape of City Square.

\section{DESIGN PRINCIPLES AND DESIGN OPERATION INSISTED IN ECOLOGICAL DESIGN OF URBAN WATER LANDSCAPE}

In ecological design of urban water landscape, people should insist on design principles to finish the design operation.

\section{A. Principles Insisted in Ecological Design of Urban Water Landscape}

Principles insisted in the ecological design of urban water landscape mainly include the principle of nature priority, the principle of new process and the principle of adjusting measures to local conditions.

The first is the principle of nature priority. The ecological design of water landscape of city square should first reduce the influence of human on natural environment, use reasonable design methods to protect natural resources and fully exert the function of natural resources on the basis of reasonable use. [7] This principle bases on meeting the requirements of natural environment and returns the nature and fully exerts the function of nature, and then ensures the integrity of the environment and human life.

The second is the principle of new process. In reality, on the basis of scientific and technological advance, the urban landscape design also develops. We can adopt the idea of ecological design and use new design materials and new process to design. The principle of new process stipulates to use natural landscape materials to replace artificial design materials. [8] It is very similar to the opinions of Chen Liya in the Discussion on Application of Water Landscape of City Square. On the basis of comprehensively using elements such as light and sound, it makes the effects of water landscape more satisfying and better meets the requirements of water landscape design of city square.

The last is the principle of adjusting measures to local conditions. In the design process, different cities need to 
combine with the practical situation, ensure to integrate with urban culture and health and comprehensively consider design elements in design. For example, areas with abundant water resource need to establish large-scale water landscape to effectively reduce the consumption of water resource. [9] Drought regions need to plan the scale of water landscape design and adopt punctate or linear pattern of water landscape design, to ensure the reasonable water landscape design of city square.

\section{B. Analysis on Ecological Design and Operation of Water Landscape in City Square}

The ecological design of water landscape in city square should:

The ecological design of water landscape of city square needs to combine with the design plan of urban development needs. It should base on practical development situation of the city and define the current situation of urban development. Firstly, it should take local culture of the city as the main basis [10] and combine with local characteristic culture to design and take city characteristics as the main frame, so as to ensure the water landscape of the square more satisfying.

Besides, we need to build circular water landscape system. In urban construction, the grounds harden. The square design has replaced natural vegetation with large area of impermeable hard materials. It can effectively enhance the natural permeability of the ground surface [11]. The ecological design of water landscape should pay attention to the design of urban ecological environment, establish circular water landscape system and then realize the coexistence with the environment. Meanwhile, the water landscape design of the square also needs to improve the permeability performance of the space around, make the best of natural rainfall and ensure the water resource back to the soil can supplement the underground water [12], and finally form good ecological water landscape as well as lay solid foundation for reasonable ecological water landscape design.

Finally, the water landscape sculpture design of city square needs to reasonably allocate aquatic plants. In order to prevent the deterioration of water quality, the design should allocate corresponding aquatic plants. Aquatic plants will change in different seasons. It can enrich the stratification of landscapes of water landscape design of city square and make the most of ecological effect of plants. The allocation of aquatic plants needs to combine with optimization of plants brought by the water quality. The forms strewn at random attract the attention of more people and let urban environment better conform to the requirements of people. It is similar to the opinions of Song Ge in the research of Discussion on Water Landscape Design of City Square. At the same time, it can truly pass on the city culture to urban residents and then guarantee the life of them.

The quality of the environment and the life of people as well as the development of the society are associated with each other. Once the environmental design is not qualified, it will bring pressure for the life of people and very likely influence the health of people. It goes against the harmonious development of our society. Therefore, we should attach great importance to the water landscape design of city square and ensure the reasonability of the design.

\section{CONCLUSION}

This article mainly focuses on four aspects. Firstly, it analyzes the relationship between water landscape of city square and city square. Secondly, it analyzes the characteristics of water landscape sculpture of city square. Thirdly, it analyzes the current situation of the design of water landscape sculpture of city square. Fourthly, it analyzes the design principles and design operation insisted in ecological design of urban water landscape. The design of the current water landscape sculpture of city square should comprehensively consider the design factors and let the design of water landscape sculpture of city square conform to the influencing factors of city structuring. So it can ensure the design of water landscape sculpture of city square to better meet the requirements of city people for beautiful city environment. In addition, at the present stage, problems exist in the ecological design of water landscape of city square. These problems have negative impacts on the design of beautiful city. Therefore, it has become important task of related design departments to solve these problems and they should pay great attention to it.

\section{REFERENCES}

[1] Ming Wenhui, Ming Baoyun, $\mathrm{Hu} \mathrm{Yu}$ etc. "People Oriented" City Square Planning and Design - The Basis of Youyi Square Planning and Design in Baotou City [J], Huazhong Architecture, 2010, 28 (12): 92-93

[2] Ming Wenhui. Planning and Design of Pleasant City Square for Citizens [D], Xi'an University of Architecture and Technology, 2005.DOI: 10.7666/d.y841666

[3] Lv Yin. First Exploration of Water Landscape Art and Design of City Square [D], Xi' an University of Architecture and Technology, 2005, (02) : $12-45$

[4] Zhang Yuming, Song Yuyan. Exploration on Ecological Design of Water Landscape of City Square [J], Journal of Shandong Jianzhu University, 2011, 26(6):571-574

[5] Zhao Zaixu, Tao Tao. Discussion on Water Landscape Design of City Square - Take Chongqing Sanxia Square as an Example [J], Chongqing Architecture, 2010,09(6):15-18

[6] Yin Xigang. Ecological Design of Water landscape of City Square [J], Beijing Agriculture, 2014, (18):247-247

[7] Xu Hua. Research on Artificial Waterscape Design Elements of City Square - Take Chengdu City as an Example [D], Southwest Jiaotong University, 2014, (45) 34-78

[8] Chen Liya. Discussion on Application of Water Landscape of City Square [J], Urban Construction Theory Research (electronic edition), 2013, (9): 45-86

[9] Wang Lu. Analysis on Art Design of Water Landscape of City Square [J], New Material New Decoration, 2013, (9):136-256

[10] Ma Ze, Lian Zhenxi. Analysis on Water Landscape Design of City Square [J], Beauty and Age, City, 2014, (1):18-18

[11] Zhu Yanfei, Zhou Xiaoru. Discussion on Water Landscape Creation of City Square Design [J], Art Panorama, 2012, (3):117-117

[12] Zhang Xun. Research on Water Landscape Design of City Square [D], Nanjing Tech University, 2008, (56) : 45-98

[13] Song Ge. Discussion on Water Landscape Design of City Square [J], Three R's (Education and Teaching Research), 2012, (32):294-324. 